\title{
El testimonio de la imagen perdida: representación cinematográfica de la masacre histórica
}

\author{
L'image manquante | Rithy Panh | 2013 \\ Santiago Martín López Delacruz* \\ Facultad de Información y Comunicación, Universidad de la República, Uruguay
}

Recibido: 30 de mayo 2017; aceptado: 7 de septiembre 2017

\begin{abstract}
Resumen
El presente trabajo de investigación tiene como objeto de estudio el filme camboyano La imagen perdida (L'image manquante según su título original). Realizado en el año 2013, es un documental escrito y dirigido por Rithy Panh que expone el genocidio ocurrido en Camboya entre 1975 y 1979 durante el régimen dictatorial comandado por Pol Pot y el ejército de los Jemeres Rojos. El análisis se enmarca sobre tres líneas de estudio: observar la problemática de la representación en el documental subjetivo, aproximarse a la relación que existe entre el cine y realidad, y examinar la condición estética de dicha representación a través de la utilización de la imagen. El objetivo del trabajo es ofrecer un acercamiento a la forma de representación cinematográfica cuando debe retratar un genocidio o una masacre histórica, donde se apela al relato de un mundo histórico a través del concepto de la representación, y a la imagen como testimonio de lo vivido a través de la memoria y el recuerdo.
\end{abstract}

Palabras clave: Cine-documental | historia | estética cinematográfica | representación.

Testimony of the lost image

Abstract

The following research work is about the Cambodian film L' image manquante (original title).This documentary was produced in 2013, written and directed by Rithty Panh. The film shows the genocide that took place in Cambodia between 1975 and 1979 during the dictatorial regime of Pol Pot and the Khmer Rouges' army. This research follows three lines of study: observing the representation nuisance in the subjective documentary, resolving the relationship between cinema and reality and examining the aesthetic condition of the representation through image. This work aims to offer an approach to the cinematographic representation of genocide or a historical massacre, using the story of a historical world through the concept of representation. Altogether using image like a testimony of lived moments through memory and remembrance.

Key words: Documentary films | history | cinematographic aesthetic | representation

\section{Introducción y planteamiento del problema}

"El yo pasado, lo que ayer sentimos y pensamos vivo, perdura en una existencia subterránea del espíritu. Basta con que nos desentendamos de la urgente actualidad para que ascienda a flor de alma todo ese pasado nuestro y se ponga de nuevo a resonar." Julio Ortega y Gasset (1917)

Con cifras que rondan entre el millón y medio y los tres millones de víctimas mortales (Burucúa y Kwiatkowski, 2014:13), entre ejecutados, torturados y desaparecidos, la dictadura acontecida en Camboya durante la década de los setenta se ocupó de la persecución de todo ciudadano camboyano que no se mostrara leal al Gobierno o a las medidas político-sociales que el mismo imponía en el país.

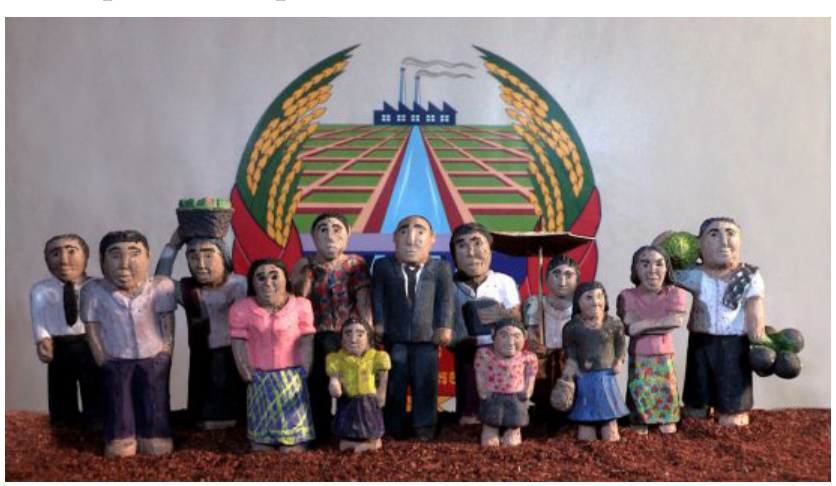

* santiagolopezdelacruz@gmail.com 
La imagen perdida (Limage manquante; 2013, dirigida por Rithy Panh) narra los actos criminales que dicho régimen perpetró al pueblo camboyano, entre las numerosas ejecuciones en masa, las diversas torturas físico-psicológicas utilizadas por el Gobierno dentro del contexto civil del país, el uso de la esclavitud por medio del trabajo forzado y la persecución de todo acusado de sedición. Para ello, la obra recrea el contexto político social del país y la situación del pueblo camboyano sumido en la dictadura por medio de muñecos, maquetas y variados elementos modelados en arcilla. ${ }^{1}$ La voz en off del propio director narra los hechos apoyándose en un marco histórico-temporal determinado y según su propia historia de vida en tal período. ${ }^{2}$

En el marco de la presente investigación sobre la representación documental de acontecimientos históricos de genocidio o de masacre, se analizarán tres aspectos complementarios entre sí, pero que resultan pertinentes sobre el filme en cuestión:

A) Analizar la película de Panh en cuanto a su condición de obra pautada desde la reflexión subjetiva y personal del realizador.

B) Comprender la resolución del director sobre su propio testimonio histórico, para verificar si intenta relacionarse con la realidad del mundo histórico al que alude.

C) Considerar el alcance de la imagen como forma pertinente de representación del dolor, al tener en cuenta la propia experiencia del realizador, tanto en el haber vivido el régimen dictatorial de modo activo como participante directo del suceso, como en el discurso que plantea sobre el acontecimiento.

Si bien el documental presenta imágenes de archivo durante el metraje, resulta necesario delimitar el análisis al uso de los muñecos como elemento central del objeto de estudio. Por lo tanto, la problemática del trabajo indaga sobre la forma en la que La imagen perdida, en tanto obra de reflexión subjetiva, se vincula con la realidad a la que alude a través de la representación del dolor en imágenes.

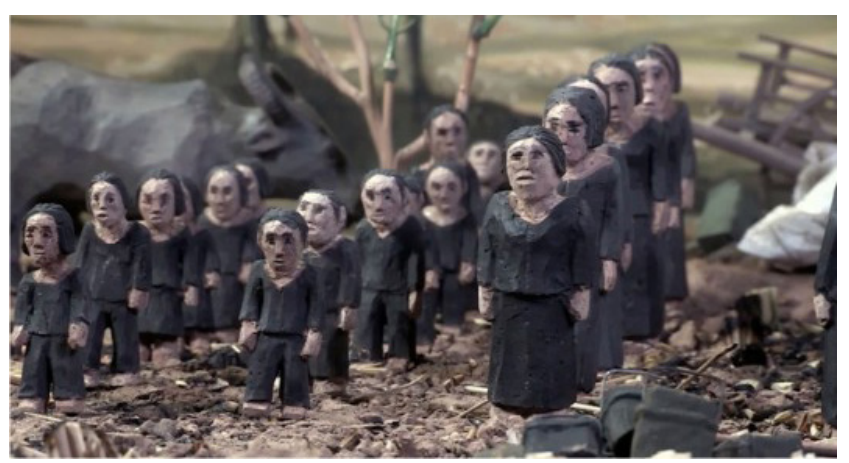

\section{Líneas de análisis}

Se tomará como base una serie de planteamientos teóricos que analizan diversos aspectos de la problemática de las representaciones de la masacre histórica en el documental seleccionado, divididos en tres ejes principales: la presencia del documental desde lo subjetivo, el vínculo del cine con la realidad material, y el poder de la imagen fílmica como forma de representación.

En primera instancia será pertinente explicitar un análisis acerca del documental per se, y su condición de obra subjetiva, para indagar de qué manera se transforma en portavoz de un punto de vista determinado, a la vez personal e íntimo adscripto al trabajo reflexivo.

A lo largo de los años, el documental se ha visto compuesto por una serie de corrientes taxonómicas, que lo han enmarcado según el tipo de discurso a utilizar. De esta manera, la tradición histórica documental ha sido marcada por la eclecticidad de sus discursos. Una de esas tantas aristas es la propuesta por el documental subjetivo, un tipo de discurso que resignifica la lectura del pasado a través de la propia subjetividad de los realizadores, al encontrar verdades parciales y provisorias, pero profundamente encarnadas y operativas para construir una memoria cercana, desde lo individual hasta lo colectivo (Piedras, 2009).

En segunda instancia, será importante indagar en la relación que La imagen perdida posee con la realidad del mundo histórico al que alude, al observar si su particular elección estética establece puntos de conexión o de conflicto con ella.

¿De qué manera una técnica basada en la animación -o en el uso parcial de ella-, puede tener contacto con la realidad al comportarse como imagen fílmica? ¿Dicha elección estética afecta la condición realista del testimonio? ¿Puede participar una representación de carácter cuasi-infantil en el devenir histórico del mundo?

Se tendrá en cuenta el aporte del teórico André Bazin, figura central de las teorías realistas, en cuya obra ¿Qué es el Cine? ${ }^{3}$ explicita las razones por las que el Cine debe tomar como materia prima la realidad, desde lo puramente estético hasta incluso, lo ontológico.

Por último, surgen otros factores de carácter problemático que afectan la condición misma de la imagen, y su condición de documento o registro de los acontecimientos cotidianos y universales. Esta condición, en tanto testimonio de hechos cruentos, es un terreno complejo en el cual se adentraron autores como Jacques Rancière o Georges Didi-Huberman. 
El problema de la imagen no surge solo por la explicitud de lo que intenta exponer, sino que es en el momento en que asume su condición de retrato del horror o del sufrimiento, en donde entran en tensión diversos factores sobre el vigor y la tolerancia de lo visual.

\section{La voz del yo en el documental}

En gran parte del metraje, Rithy Panh guía y narra con su voz los hechos acaecidos durante el régimen dictatorial de Camboya, de los cuales fue víctima en su infancia. Ubicado ya en la madurez, se toma el tiempo para reflexionar sobre lo acontecido, al partir desde una subjetividad que en todo momento lo condiciona: describe el horror al mismo tiempo que ambiciona recordarlo mediante el manejo de muñecos de arcilla, intenta un acercamiento compasivo a la vez que fracasa en encontrar imágenes o registros que asimilen el hecho.

Una de las metas del documental subjetivo es tomar herramientas por fuera de la estructura de los documentales clásicos, ya que «se basa en la imposibilidad del documental clásico de dar cuenta de una verdad histórica sobre los hechos traumáticos de la historia reciente» (Piedras, 2009). De este modo, el documental asume la primera persona como articulador de lo expuesto, ya que dota a la obra de una carga trascendente en cuanto a lo íntimo y lo personal.

La imagen perdida evoca continuamente el factor subjetivo, ya que presenta a Rithy Panh en una doble faceta: como director de una obra cinematográfica y como el testigo más cercano a la narración de su obra, dada su condición de víctima del genocidio. La voz del director se une a la línea narrativa del filme bajo un perfil propio y particular.

El documental subjetivo asume un gran peso a todo lo referido a la identidad, ya que el cineasta se decide a escarbar en el pasado para dar cuenta de las "deudas emocionales" (Ruffinelli, 2010).

Por otro lado, Bill Nichols establece que los documentales presentan cuatro modalidades de representación: la modalidad expositiva, de observación, interactiva y reflexiva. La última de las modalidades, la reflexiva, indaga a juicio del autor en el hecho de que: «la representación del mundo histórico se convierte, en sí misma, en el tema de meditación cinematográfica» (1997:93).

La imagen perdida se adscribe en dicha modalidad de representación. Al inicio del documental, Panh reflexiona sobre el modo de representar su historia. Mientras coloca imágenes de una persona que talla y pinta un muñeco de arcilla, expresa en off:

«Los recuerdos están aquí, ahora. Golpean mis templos, me gustaría ahuyentarlos. Con tierra y agua, con los muertos y los campos de arroz, con las manos vivas, hacemos un hombre. No hace falta mucho, basta con que te lo creas»

Al asumir el carácter subjetivo del documental, el realizador pone en jaque su modo de representar el pasado, a la vez subjetivo y personal, pero también colectivo y enmarcado dentro de una crónica socio-histórica. La decisión de narrar los hechos mediante muñecos de arcilla suscita una reflexión sobre hasta qué punto el documental tiene relación con la realidad, y de que forma el espectador acepta dicho contrato de verosimilitud.

¿Puede la decisión estética del realizador afectar al testimonio del dolor expresado aquí como un documento fílmico? Panh explicita que la decisión dependerá de la expectativa que el espectador tendrá, y de allí su indagar en el nivel de credibilidad sobre el tema. El modo del documental en primera persona se interroga, entonces, sobre desde que voz representar más que en el qué representar; no se preocupa en que se vean las "costuras" de cómo fue su realización, sino que precisamente es desde esa declaración de intenciones de la que parte para asimilar el mundo histórico al que intenta referir.

Mediante la galería de muñecos, el documental deja bien en claro a la problemática a la que alude. Se asume la veracidad de los hechos cuando se sabe qué muñecos representan a los camboyanos oprimidos y cuales a los soldados del Ejército. Reconocemos que las maquetas de casas, terrenos y edificaciones representan a la Camboya sumida en la miseria y la auto-destrucción por la aplicación del off que contextualiza el tema.

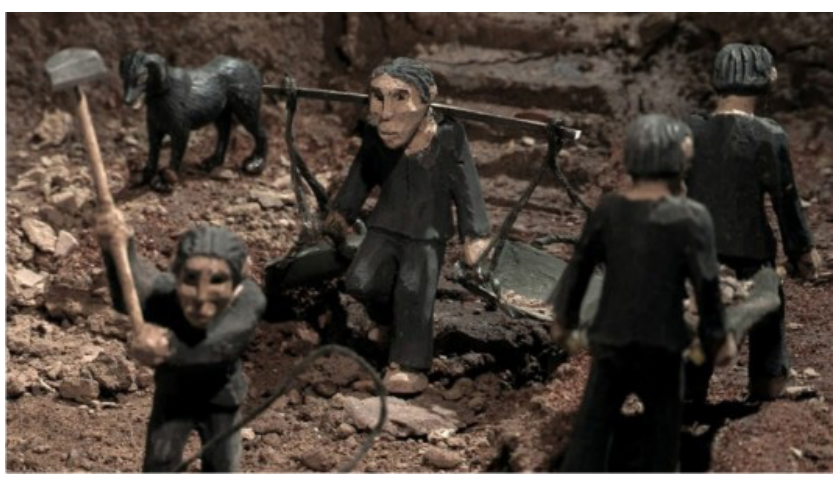

La propuesta de Rithy Panh ofrece reflexión en base a lo subjetivo a un doble nivel: en el de la representación del dolor a causa del genocidio (al apelar a un sentido emocional), y en explicitar los porqués de representar bajo ese recurso (un ejercicio casi metanarrativo dentro 
de la propia película), lo que provoca la participación del espectador en ambos procesos. Cómo señala Nichols: «el documental reflexivo lleva al espectador a un estado de conciencia intensificada de su propia relación con el texto y de la problemática relación del texto con aquello que representa» (1997:97).

La representación del dolor en La imagen perdida resulta de la simbiosis de lo emocional con lo reflexivo; Panh utiliza los recuerdos como forma de canalizar las interrogantes que le agobian del pasado. Desde el presente, juega con la estética de la representación para desfragmentar su historia y plasmarla desde un perfil de intercambio con su espectador. Al mismo tiempo que el director moldea las facciones en los rostros de sus muñecos mediante arcilla, construye la arquitectura de emociones perdidas y sensaciones de miedo, desesperación y angustia de las víctimas a las que recuerda. Sin embargo, lejos se está de alguna respuesta esclarecedora sobre lo vivido.

Este no-hallazgo de soluciones parece hacerse un lugar desde los recuerdos más profundos, que roza entre lo personal y lo íntimo. Panh logra que el documental, en ese camino utópico de dolor anclado desde el presente, capte la atención desde la particularidad de su representación:

«Es preciso encontrar el modo de enfrentarnos a lo infilmable, de invocar una imagen de lo que no tiene rostro ni medida, lo que no se ve y sin embargo palpita de presencia, irradiando el presente. El documental aspira entonces a ser un medio para revisar el modo en que (...) nuestra memoria se constituye, entre olvidos y clichés» (Breschand, 2004:47)

Representar lo infilmable, lo que no tiene rostro ni medida, resulta en La imagen perdida el verdadero testimonio del dolor pasado. El documental no utiliza entrevistas con testimonios reveladores, ni sienta sus bases sobre el uso completo de imágenes de archivos. Prefiere bucear, casi de forma inductiva, sobre la problemática que aborda: Panh realiza un viaje al interior de sus recuerdos, exponiéndose y confrontándose con el mundo material; lo subjetivo y lo histórico se encuentran, y el dolor no se enmarca en "estrategias sensacionalistas", sino en la forma en que se puede y debe representar lo irrepresentable. Allí se encuentra la naturaleza propia del documental subjetivo.

\section{La condición estética ante la realidad histórica}

¿Pero de qué forma la realidad a la que el documental refiere es partícipe en la reflexión de su propia representación? Si una de las problemáticas primordiales del género documental es la representación de la realidad, la labor de Panh consiste en plasmar referencias del mundo histórico al cual testifica sin evadir la peculiar estética que asumió para elaborar el discurso sobre la tragedia de la dictadura camboyana.

Este discurso, si su objetivo es retratar la realidad de lo acontecido, requiere un trabajo tanto en lo formal de la expresión como en las voces de lo narrado; mediante la verificación de su propuesta, tanto de la imagen como del contenido. André Bazin (1990) advierte esta disociación como uno de los motivos de anclaje de la realidad en lo fotográfico: la confusión entre el factor estético y el psicológico repara tanto en la representación esencial del mundo (realismo verdadero) como en la ilusión de las formas (pseudorrealismo).

Cuando Rithy Panh coloca como representantes de la realidad a simples muñecos de arcilla en vez de otros recursos más tradicionales (entrevistas, seguimiento, etc.), cabe preguntarse qué tan lejos se encuentra de esa realidad a la que insinúa en su discurso en off. Panh participó de esa realidad a la que representa. La vivió en la infancia, la asimilo a través del dolor, e intenta verificar lo perdido a través de las reminiscencias de su madurez, pero ¿de qué manera la realidad encuentra lugar en una decisión estética tan particular?

La elección estética de La imagen perdida no intenta copiar la realidad, sino brindarle un nuevo sentido, al posibilitar que se presente de múltiples maneras, algo que Bazin llama "virtualidades estéticas", que brinda que la imagen fotográfica revele lo real, y "transfusión" de la realidad, desde la cosa a su reproducción inmediata $(\mathrm{Ba}-$ zin, 1990:27-28). Así, la representación del mundo en miniatura no evade a la realidad. Por el contrario, revela nuevas aristas del discurso de lo ocurrido, al exponer elementos del cotidiano de lo real que a simple vista resultaban inaccesibles frente a la ausencia de lo cinemático.

Sin embargo, es muy delgada la línea que supone la veracidad de lo real. La decisión de Panh de dotar a su obra de un perfil influido por las técnicas del cine de animación expone una interrogante crucial con la realidad histórica: no vemos hechos ni escuchamos voces arraigadas a la realidad de un mundo histórico reconocible, sino que la responsabilidad de conectar con lo real radica exclusivamente en la representación, en la forma de lo narrado.

Surge allí, un estado de tensión entre lo formal y la veracidad del contenido, entre la realidad histórica de la nación camboyana y la condición estética del testimonio brindado. El documental se encuentra en la línea difusa que lo separa de las narraciones de ficción, puesto que 
toma el riesgo de construir un mundo influido plenamente por la realidad de un pasado histórico pero alejado de una forma de representación a simple vista reconocible y veraz.

Cuando Panh expone las ejecuciones en masa realizadas por el ejército camboyano, evoca a huellas de su memoria, y las imágenes terminan por volverse trazos de la propia realidad. Allí, no podemos no reconocer que dicha representación toma lo esencial, lo original de la realidad para devolverle al mundo un proceso en donde el realizador también aporta sus propios patrones, sean los estéticos, sean los psicológicos. De esta manera, el cine termina participando activamente en lo ontológico, de todo aquello que es y que forma parte del proceso del ser.

El objetivo de la teoría realista, según Bazin, era expresar que «entre el cine y la realidad hay una relación existencial, una continuidad profunda, pues ambos se emparentan ontológicamente» (Casetti, 1994:43). En el documental, esta relación se expone de forma trascendente: el director habla de un hecho histórico que vivió, al cual su infancia se adscribió y del que su familia fue víctima. El trazo histórico que realiza con su película refiere ineludiblemente a un mundo material que lo contiene, pero donde también confluye su universo personal.

En La imagen perdida, el proceso cinematográfico de representación se confunde con la experiencia íntima del realizador. Y viceversa: los procesos emocionales encuentran sentido testimonial al inscribirse en el camino de lo fílmico. Es un vínculo recíproco y solidario: el cine participa de la existencia, y la existencia encuentra su forma de representación en el cine.

El cine encuentra la realidad y viceversa, la realidad termina por aceptar y adecuar las convenciones de lo cinematográfico. Según Burucúa y Kwiatkowski (2014) es posible entender un hecho límite como lo son los genocidios a través de la inclusión de su testimonio en marcos retóricos y estéticos, al distanciar emocionalmente la dicotomía sujeto-objeto, para intentar develar algo que sea contundente y real.

Un caso similar, en cuanto a antecedentes cinematográficos, puede encontrarse en el filme Los rubios, ${ }^{4}$ en donde la representación de lo real queda condicionada a la decisión íntima de la realizadora Albertina Carri de exponer lo fragmentario de su pasado en construcción de maquetas y utilización de muñecos de Playmobil como método formal de búsqueda de memoria e identidad.

Esta decisión propuesta por Carri recoge varios puntos de similaridad con la de Panh, puesto que la realizadora argentina no responde con un panfleto o un discur- so de justificación histórica, sino que responde con una apuesta por la estética, como territorio en donde dar la vida o vivir vale la pena (Aguilar, 2010).

\section{El poder de la imagen frente al dolor}

Es de importancia preguntarse por el impacto de las imágenes del documental, puesto su relación tan ligada a la realidad, a tal punto de ser representación y testimonio casi de manera simultánea. ¿Cuál es el objetivo final del filme en la elección sus imágenes y cuáles son las impresiones que provoca dicha estética?

Cabe señalar que Jacques Rancière explicita la concepción esencial de las imágenes, al establecer que: «La imagen no es el doble de una cosa. Es un juego complejo de relaciones entre lo visible y lo invisible, lo visible y la palabra, lo dicho y lo no dicho» (2010:94). Al igual que las teorías realistas, Rancière no considera a la imagen como doble o copia de la realidad, sino que la interpreta como algo presente en la realidad y que forma parte de ella, enmarcándose de esta forma en una referencia discursiva de carácter complejo (2005:183).

Pero también, Rancière explicita que «el cine documental es una modalidad de ficción, más homogénea, y a la vez, más compleja». Esto conlleva una interrogante sumamente interesante sobre lo propuesto por Panh, ya que el testimonio que plantea en última instancia es una representación ficcional, más allá de emparentarse con una situación histórica.

La propuesta radical de Rancière expondría que $\mathrm{La}$ imagen perdida es ante todo una ficción, qué si bien evoca la representación del dolor y utiliza la imagen como testimonio, no termina de perder en absoluto su raíz ficticia, su condición de propuesta creada para un propósito dentro de lo narrativo. Igualmente, no se debe confundir en este ejercicio ficticio lo subjetivo con lo tendencioso.

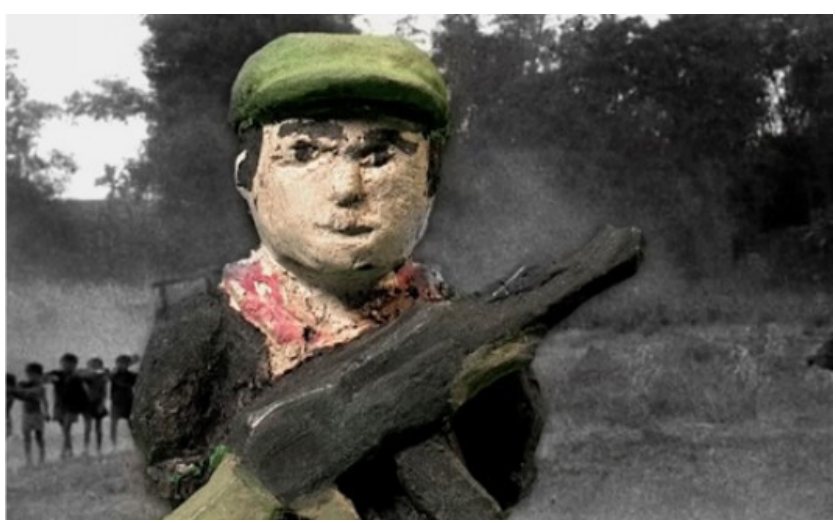


Las imágenes expuestas en la cinta no hacen gala de posturas maniqueístas. Por el contrario, respetan una narración solemne y sin golpes efectistas, y se conjugan en armonía con el relato en off del director. Un claro ejemplo radica en una escena en la que, mediante los muñecos, un niño de nueve años denuncia a su madre ante al ejército por haber robado mangos. Mientras el muñeco del niño tiene un brazo levantado en símbolo de apoyo al régimen, la madre está pronta para ser ejecutada. Panh utiliza la siguiente frase:

"La madre cierra sus ojos, ¿es para guardar la imagen de su bijo? Ella calla”.

Decide no mostrar la ejecución. Sin embargo, la poética de la escena no minoriza la crueldad de la situación. De esta forma, el concepto propuesto por Rancière de "imagen intolerable" se hace presente, aun cuando se encubren las formas más explícitas y emocionales de representación, en el planteamiento sobre que vuelve a una imagen intolerable, si el solo hecho de que nos cause dolor e indignación o hacerla partícipe del colectivo (Rancière, 2005:85).

Las imágenes del filme son complejas a múltiples niveles: es la prueba fehaciente del pasado de Panh, es la clara referencia a un mundo histórico asimilado por el ser humano y es también una herramienta que obra como recuerdo. El impacto que el espectador posea (o no) respecto a dicho testimonio visual dependerá, en primera instancia y tal como Panh lo expresó, de su horizonte de expectativas. En segundo término, de la capacidad propia de la imagen para retratar lo que no se puede representar de otra forma, lo que solo una imagen puede narrar.

Es relativamente costoso separar el impacto de la realidad del impacto de la imagen, cuando la propia obra precisamente lo que hace es colocar en tensión dos variables: la innovación estética y la veracidad narrativa. Además, porque en mayor o menor medida «somos vulnerables ante los hechos perturbadores en forma de imágenes fotográficas como no lo somos ante los hechos reales» (Sontag, 2006:236).

Si bien La imagen perdida no posee ningún tipo de documento (sea visual, escrito o hablado) que afecte a la sensibilidad por un uso crudo de la imagen, resulta innegable la trascendencia de su testimonio: es en la forma elegida por Panh en donde se encuentra el mayor impacto, ya que continuamente nos refiere a lo ya vivido, a lo que ya es parte de la Historia, a lo que, en última instancia, es real. La sugerencia poética de las imágenes resulta de un calibre superior a una sobreexposición del horror mediante el retrato de lo cruel. Porque sabemos que detrás de dicho discurso, sigue habitando el dolor latente y la angustia contenida de una Nación en las formas más armoniosas del lenguaje cinematográfico.

El equilibrio entre imagen y palabra resulta fundamental en el documental, no solo porque representa una decisión formal, sino que primordialmente se conforma como documento de un mundo histórico, un registro de voces y hechos, donde subyace el peso de lo subjetividad de Panh en defensa de lo colectivo de su propio pueblo, en medio a la reflexión y el tributo.

Rancière, ligado a esto último, entiende que allí está la función real de las imágenes intolerables: «la fuerza del silencio que traduce lo irrepresentable del acontecimiento no existe sino por su representación: la potencia de la voz opuesta a las imágenes debe expresarse en imágenes» (2005:93). La imagen debe asemejarse como el valor final de lo irrepresentable, debido a que es la representación en sí y por sí misma, atrae y aísla desde la experiencia a todo aquel que la vea.

La delgada línea que separa lo representado de lo real en La imagen perdida se emparenta desde el proceso mismo de la imagen, operada y seleccionada con base en lo subjetivo, pero sin desatender su función semántica: toda imagen significa, y se presenta viva ante lo que registra, testimonia o alude. Como expone Georges Didi-Haberman: «La imagen arde por la memoria, es decir que todavía arde cuando ya no es más que ceniza: una forma de decir su esencial vocación por la supervivencia, a pesar de todo» (2007:36).

Como se ha visto, Rithy Panh elabora un discurso que suscita una serie de problemáticas, puesto que toma un camino diferente al expuesto por otros documentales de gran relevancia histórica, como Nuit et Brouillard (Alain Resnais, 1955) y Shoab (Claude Lanzmann, 1985), o los recientes trabajos The Act of Killing y The Look of Silence (Joshua Oppenheimer, 2012;2014). Porque el problema en La imagen perdida radica en la representación del dolor que se desprende desde las propias estrategias de representación, tal y como sugiere la categoría subjetiva en la que, como documental, se enmarca.

De una manera simbólica, La imagen perdida evocaría, casi como si de un homenaje se tratara, un memorándum las víctimas del genocidio camboyano. Los seres humanos asesinados, torturados y desaparecidos durante el mandato militar en el país quedarán para siempre en la 
memoria de la imagen fotográfica. Ella será la encargada de mantenerlos vivos a través de la reproducción cinematográfica.

\section{Consideraciones finales}

La representación del dolor, desde un punto de vista reflexivo, aparece cuando el sentimiento de lo colectivo, los rostros sufrientes tallados en arcilla, confluye con la evocación personal de recuerdos de Panh. El documental no solo es una crónica histórica, sino que se apuntala como participante mismo de la existencia por medio de la representación fílmica, el único discurso capaz de solventar el dolor, el recuerdo y la tragedia a través de su materia prima: la realidad.

Seguramente, al aludir a la imagen perdida, no hablamos de una imagen en sí, sino de algo escurridizo que la historia del pueblo camboyano (y de otros tantos pueblos) ha sepultado, han intentado borrar y, por ende, transformado en un destino utópico. De forma paradójica, la imagen que Panh no ha encontrado puede ser aquella que tanto anheló hallar: la imagen de la verdad.
Observar de que forma la representación de la masacre histórica se hace presente en el discurso fílmico, en este caso, de un documental. La imagen perdida es un filme que se enmarca dentro de una categoría reflexiva de representación, preocupándose tanto por la forma de representar como por el mundo histórico al que alude. A su vez, posee un vínculo particular con la realidad particular: elige una forma de narrar que utiliza un entramado estético pocas veces visto en el género, que posibilita revelar nuevos aspectos del mundo real, de manera tal que su voz narrativa se vea revalorizada por la reproducción cinematográfica.

Resulta necesario expresar el inmenso valor que poseen las obras documentales, tanto en su forma de registro como en las múltiples aristas que lo componen, desde las estéticas hasta las estrictamente relacionadas al contenido.

En este caso, la oportunidad de ejercitar la memoria y la imaginación a través de la reflexión anclada en lo histórico, conlleva a tener presente los diversos grados éticos y emocionales a los que la representación cinematográfica intenta, por lo menos, aproximarse y ofrecer un recordatorio pertinente a la conciencia colectiva.

\section{Referencias}

Aguilar, Gonzalo (2010). Nuevos mundos: ensayos sobre el nuevo cine argentino. Buenos Aires: Editorial Arcos.

Bazin, André (1990) ¿Qué es el Cine? Madrid: Ediciones Rialp.

Breschand, Jean (2004). El documental. La otra cara del cine. Madrid: Paidós Ibérica.

Burucúa, José Emilio; Kwiatkowski, Nicolás (2014). Cómo sucedieron estas cosas. Buenos Aires: Katz Editores.

Casetti, Francesco (1994). Teorías del Cine. Madrid: Cátedra.

Didi-Huberman, Georges (2007). Cuando las imágenes tocan lo real. Madrid: Área de Edición del Círculo de Bellas Artes.

Nichols, Bill (1997) La representación de la realidad. Madrid: Paidós Ibérica.

Ortega y Gasset, Julio (1917). El espectador. Tomo II. En Obras completas (1963). Madrid: Ediciones Castilla.

Piedras, Pablo (2009). El problema de la primera persona en el cine documental contemporáneo. Buenos Aires: Facultad de Ciencias Sociales de la Universidad de Buenos Aires.

Rancière, Jacques (2010). El espectador emancipado. Buenos Aires: Ediciones Manantial.

Rancière, Jacques (2005). La fábula cinematográfica. Reflexiones sobre la ficción en el cine. Barcelona: Paidós Ibérica.

Ruffinelli, Jorge (2010) Yo es/soy "el otro": Variantes del documental subjetivo o personal. Acta Sociológica, N53.

Sáenz Valiente, Rodolfo (2006). Arte y técnica de la animación. Buenos Aires: Ediciones De La Flor.

Sontag, Susan (2006). Sobre la fotografía, Ciudad de México: Santillana Ediciones Generales.

1 No confundir con stop-motion, referida a la técnica de animación crorporea realizando el registro cuadro por cuadro. En el documental, los muñecos están estáticos. Véase Sáenz Valiente (2006).

2 Cabe señalar que el realizador Panh ya se ha ocupado previamente del genocidio camboyano en su filmografía. Las anteriores obras que abordan el tema son los documentales Site 2. Aux abords des frontières (1989), Bophana, une tragédie cambodgienne (1996), S-21, la machine de mort Khmère rouge (2003) y Duch, le maître des forges de l'enfer (2011); y el filme de ficción Neak sre - Les Gens de la Rizière (1994). 
Recordar que la obra Qu'est-ce que le cinéma? (título original en francés) es una colección de artículos que Bazin escribió para la revista de crítica Cahiers du Cinéma, de la que fue fundador en 1951. El artículo seleccionado para el tema del trabajo es "Ontología de la imagen fotográfica".

$4 \quad$ Los rubios es un documental argentino del año 2003 dirigido por Albertina Carri que narra el secuestro y la desaparición de Roberto Carri y Ana María Caruso, padres de la realizadora, durante la dictadura militar argentina ocurrida en 1976. 